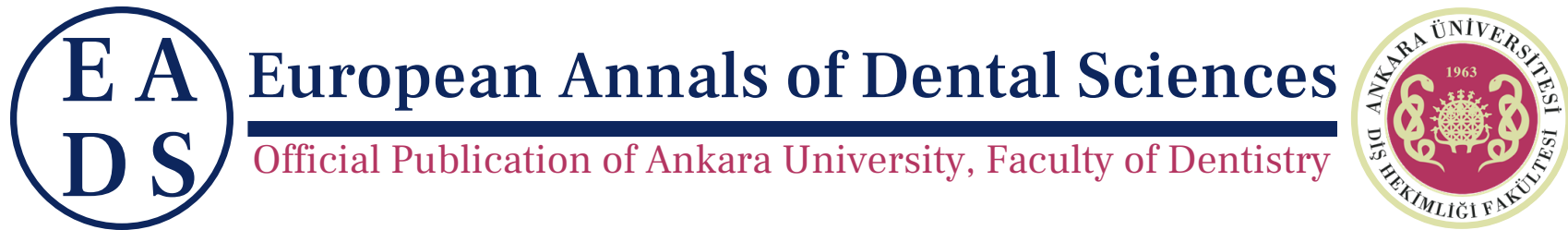

EADS, 2021, 48 (Suppl), S11-13

\title{
Evaluation of Dental Students' Awareness and Attitude about Preventive Dental Treatments: Survey Research
}

\author{
Merve Abaklı Inci $\odot^{1, *}$, Onur Agmaz $\odot^{2}$ and Hazal Ozer ${ }^{1}$ \\ ${ }^{1}$ Department of Pediatric Dentistry, Faculty of Dentistry, Necmettin Erbakan University, Konya, TURKEY and \\ ${ }^{2}$ Dentova Academy Oral and Dental Health Polyclinic, Konya, TURKEY \\ *Corresponding Author; merveabakli@gmail.com
}

\begin{abstract}
Purpose: Determination of dental students' approaches to fissure sealant applications; the widespread use and evaluation of their effectiveness of protective dental practices is extremely important. This study aims to evaluate the level of understanding and clinical attitudes of 3rd, 4 th and 5th grade students of Necmettin Erbakan University, Faculty of Dentistry on preventive dental treatments.

Methods: The first part of the questionnaire consists of 10 questions assessing the students' technical levels of knowledge with data on age, gender and educational level. In the second section analyzing students' clinical behaviors, 11 questions were asked for answers to multiple choices (always, often, sometimes, never). This questionnaire was used on the internet in an anonymous way. For statistical analyses, the IBM SPSS Statistics 25 (IBM Corporation, Armonk, NY, US) software was used.

Results: TThe questionnaire was received by 68 rd grade, 674 th grade and 755 th grade students who were previously educated on fissure sealant applications. The vast majority ( 96.2 percent) of the students involved in the study indicated that the effectiveness of fissure sealants in preventing the development of tooth decay was confirmed by strong scientific evidence. Again, 99.5 percent of the students participating in the study indicated that the justification of the application procedures for the fissure sealant was identified and understood. With the assumption that only new teeth can be applied to fissure sealants, a statistically significant difference between the classes was observed ( $<<0.05$ ); 3rd graders responded "yes" mainly. The fact that they have not yet undergone clinical training may clarify this condition.

Conclusion: Although dental students have sufficient knowledge of protective dental practices and fissure sealants, variations in understanding and implementing clinical practice procedures may be found between classes. Standardization should be provided and education / lectures on preventive dental practices should be increased to obtain the equivalent of theoretical education at the clinical level.
\end{abstract}

Key words: Dental students;dental protective applications; pit and fissure sealants

\section{Introduction}

Tooth decay is a microbiological infectious disease that can be observed in all age groups, resulting in calcified tissues being damaged and dissolved locally. ${ }^{1}$ Of all health issues, it is one of the most prevalent diseases. Tooth decays in accordance with the dietary and oral hygiene habits of the individual; it is also among the diseases that can be avoided. ${ }^{2}$

Preventive dentistry is a specialty of dentistry that uses noninvasive conservative procedures to reduce the risk of caries in population. Although the development of caries decreases over time despite preventive oral health programs, the rate of caries on the occlusal surfaces in pits and fissures still accounts for more than $80 \%$ of all caries experienced in children and adolescents. ${ }^{3}$

Fissure sealant applications are one of the most basic preventive dentistry treatments. The most effective preventive treatment method is to modify the pits and fissure areas where occlusal caries occurs at a high rate and to make the surface simple to clean. The connection between bacteria and the food source is cut with these applications and a protective barrier is formed. ${ }^{4,5}$ Application to fissure sealant; it is a painless and non-invasive technique used without removing unnecessary tissue. ${ }^{6,7}$

It is highly necessary for dentists to follow preventive strategies for early diagnosis and treatment of carious lesions and also to determine personalized treatment options based on the patient's risk of caries, in order to protect public health and reduce the incidence 
Table 1. Preventive dentistry questions included in the survey

Knowledge, opinions and attitudes regarding fissure sealant

1.I know that strong scientific evidence supports the effectiveness of fissure sealants in preventing tooth decay.

2.I know the application procedures for the fissure sealant.

3.I understand the logic of the application procedures for the fissure sealant.

4.It is possible to apply fissure sealants only to newly erupted teeth.

5.Depending on use, fissure sealants may be used.

6.The most significant factor in the effectiveness of treatment is application methods.

7.Resin fissure sealants are more effective than glass-ionomer ones.

8.Acid is suggested to increase the bonding in fissure sealant applications.

9.I acknowledge that in protective dental applications, fissure sealants have a high role and can be used in new caries.

10.In conjunction with fluoride applications, when fissure sealant treatments are applied, the risk of caries is further reduced.

of caries in society. Not only dentists; dental students should be educated in this direction as well. ${ }^{8}$ Determination of dental students' approaches to fissure sealant applications; the widespread use and evaluation of their effectiveness of protective dental practices is extremely important. This research aims to evaluate the level of knowledge and clinical attitudes of $3 \mathrm{rd}, 4$ th and 5 th grade students of Necmettin Erbakan University Faculty of Dentistry on preventive dental treatments.

\section{Methods}

This research was conducted online with 3 rd, 4 th, and 5 th grade students from the Faculty of Dentistry of Necmettin Erbakan University. Participation in the research was voluntary, and the identities of those who took part in the research were kept private. The research was conducted online with the approval of the Ethics Committee (2021/01-10). 68 rd grade, 674 th grade and 755 th grade students were included in the research.

The first part of the questionnaire consists of 10 questions aimed at assessing the technical level of knowledge of students with data on age, gender and educational level. The purpose of these 10 questions was to assess students' knowledge of the application steps of fissure sealants, the necessity of application, and the content of fissure sealants (Table 1). In the second segment assessing the clinical attitudes of students, 11 questions were asked for answers to multiple choices (always, often, sometimes, never). These questions concern the isolation, attachment and application stages of fissure sealant applications, as well as learning about the students' clinical attitudes. The questionnaire's questions were developed using case studies from the literature. ${ }^{8-10}$ Before the research, questions about the questionnaire were asked; reliability analysis was used on a pilot group in the research group in terms of understandability and word arrangement.

For statistical analyses, the IBM SPSS Statistics 25 (IBM Corporation, Armonk, NY, US) software was used. The frequency values of descriptive variables were recorded. During the data analysis, Chi-square tests and Mann-Whitney U tests were used. The $\mathrm{p}<0.05$ level was considered statistically significant in all of these analyses.

\section{Results}

68 3rd grade, 674 th grade and 75 5th grade students who were previously educated on fissure sealant applications obtained the questionnaire. 137 female (65.2\%) and 73 male (34.8\%) dental students participated in the research (Table 2 ). The average age of dental students participating in the research was 21.8.

The vast majority (96.2\%) of the students involved in the research reported that good scientific evidence supported the efficacy of fissure sealants in preventing tooth decay development. Again, $99.5 \%$ of the students involved in the research reported that they knew and understood the rationale of the application procedures for the fissure sealant. A statistically significant difference between
Table 2. Demographic data of the participants.

\begin{tabular}{ll}
\hline Variables & $\mathrm{n}(\%)$ \\
\hline Gender & $73(34.8 \%)$ \\
Male & $137(65.2 \%)$ \\
Female & \\
Grade & $68(31.9 \%)$ \\
$3^{\text {rd }}$ grade & $67(32.4 \%)$ \\
$4^{\text {th }}$ grade & $75(35.7 \%)$ \\
$5^{\text {th }}$ grade & \\
\hline
\end{tabular}

the classes was found with the assumption that only new teeth can be applied to fissure sealants ( $\mathrm{p}<0.05)$; 3rd graders replied "yes" mostly. The fact that they have not yet undergone clinical training may clarify this condition.

At the same time, students in 3rd grade answered "yes" to the suggestion that fissure sealants can also be applied to new caries; the new completion of the theoretical training in protective dental practices can explain this situation. Clinical attitudes towards fissure sealant applications were assessed; statistically significant differences were also observed between the pre-treatment prophylactic polishing grades, reading the material instructions from the manufacturer, and returning to the beginning in incorrect steps $(\mathrm{p}<0.05)$ (Table 3).

\section{Discussion}

The purpose of this research was to assess the knowledge and attitudes of the students of the Faculty of Dentistry of Necmettin Erbakan University about fissure sealants, one of the practices of preventive dentistry. It was shown at the end of the research that students in dentistry had acceptable knowledge of fissure sealants.

While there are questionnaires assessing the students of dentistry in terms of their course effectiveness when the literature is reviewed, it is shown that the number of subject-based assessment studies is limited.

Ealla et al. ${ }^{10}$ in their research; they evaluated the knowledge and attitudes of 280 dentistry students regarding fissure sealant applications. The students participating in the questionnaire have been confirmed to have a reasonable theoretical understanding of fissure sealants. On the other hand, the students participating in the survey were stated to have limited clinical practice knowledge.

A 22-question questionnaire survey was used to assess dental students' awareness and knowledge of preventive dentistry practices. The students were asked general questions about oral hygiene practices, xylitol, and fluoride, but the majority of them were reported to have received incorrect answers. As a result, it was stressed that more emphasis should be placed on preventive dentistry practices before students graduate. ${ }^{8}$

In another study published in 2016, 500 dentists were asked questions about preventive dentistry practices. Although all the 
Table 3. Questions regarding fissure sealant application procedures

\begin{tabular}{|c|c|c|c|c|}
\hline Questions & Always(\%) & Sometimes(\%) & Rarely (\%) & Never (\%) \\
\hline I refuse treatment with fissure sealant, knowing I can apply it to hidden decays. & 3.8 & 3.8 & 67.1 & 25.2 \\
\hline I replace them if the fissure sealants are partially or completely broken. & 23.3 & 41.9 & 32.4 & 2.4 \\
\hline $\begin{array}{l}\text { In fissure sealant applications, isolation is the most important factor that ensures } \\
\text { effective bonding. }\end{array}$ & 57.6 & 35.2 & 7.1 & 0.1 \\
\hline $\begin{array}{l}\text { Acid application is the most significant factor that ensures successful bonding in } \\
\text { fissure sealant applications. }\end{array}$ & 35.7 & 56.2 & 6.7 & 1.4 \\
\hline I clean the surface of the tooth before applying fissure sealants. & 85.2 & 12.4 & 1.9 & 0.5 \\
\hline $\begin{array}{l}\text { For optimal polymerization in fissure sealant applications, I read the } \\
\text { manufacturer's instructions. }\end{array}$ & 47.1 & 27.6 & 19.5 & 5.7 \\
\hline $\begin{array}{l}\text { I provide the most effective isolation with rubber-dam in fissure sealant } \\
\text { applications. }\end{array}$ & 20.5 & 17.6 & 40.5 & 21.4 \\
\hline In fissure sealant applications, I use cotton rolls to provide isolation. & 63.8 & 28.1 & 4.3 & 3.8 \\
\hline $\begin{array}{l}\text { I often apply fissure sealant to occlusal areas, other than pits and fissures, to } \\
\text { increase the bond. }\end{array}$ & 13.8 & 13.3 & 23.3 & 49.5 \\
\hline $\begin{array}{l}\text { If I make any mistakes during the application steps of the fissure sealant, I start } \\
\text { from the beginning. }\end{array}$ & 41 & 30 & 25.7 & 3.3 \\
\hline I do the polishing for prophylaxis before placing the fissure sealant. & 17.6 & 19.5 & 31.4 & 31.4 \\
\hline
\end{tabular}

questions were answered by only 74 percent of the physicians taking part in the study; most of the respondents are men. It was recorded that $84.2 \%$ of the participants were physicians and $48.3 \%$ had less than five years of clinical experience. Most of the participants ( 88 percent) reported as a result of the survey that they believe there is good empirical evidence regarding the efficacy of fissure sealants. ${ }^{9}$

\section{Conclusion}

Although dental students have adequate knowledge of protective dental practices and fissure sealants, discrepancies in understanding and applying clinical practice procedures may be found between classes. To receive the equivalent of theoretical training at the clinical level, standardization should be provided and preventive dental practice training / lectures should be increased.

\section{Author Contributions}

M.A.I, O.A and H.O conceived the design of the study; M.A.I, O.A and H.O acquired, analysed, and interpreted the data. M.A.I wrote the majority of the original draft of the paper. O.A and H.O participated in writing the paper. All authors approved the final version of this paper.

\section{Conflict of Interest}

Authors declare that they have no conflict of interest.

\section{Authors' ORCID(s)}

M.A.I. $\quad 0000-0003-2979-0336$

O.A. $\quad 0000-0001-9957-3447$

H.O. $\quad 0000-0002-4389-2008$

\section{References}

1. Machiulskiene V, Campus G, Carvalho JC, Dige I, Ekstrand KR, Jablonski-Momeni A, et al. Terminology of Dental Caries and Dental Caries Management: Consensus Report of a Workshop Organized by ORCA and Cariology Research Group of IADR. Caries Res. 2020;54(1):7-14. doi:10.1159/000503309.

2. Nowak A, Christensen JR, Mabry TR, Townsend JA, Wells MH. Pediatric Dentistry-E-Book: infancy through adolescence. Elsevier Health Sciences; 2018.

3. Schwendicke F, Jäger AM, Paris S, Hsu LY, Tu YK. Treating pit-and-fissure caries: a systematic review and network meta-analysis. J Dent Res. 2015;94(4):522-33. doi:10.1177/0022034515571184.

4. Cueto EI, Buonocore MG. Sealing of pits and fissures with an adhesive resin: its use in caries prevention. J Am Dent Assoc. 1967;75(1):121-8. doi:10.14219/jada.archive.1967.0205.

5. Guler C, Yilmaz Y. A two-year clinical evaluation of glass ionomer and ormocer based fissure sealants. J Clin Pediatr Dent. 2013;37(3):263-7. doi:10.17796/jcpd.37.3.38761uwwm7kpj616.

6. Feldens EG, Feldens CA, de Araujo FB, Souza MA. Invasive technique of pit and fissure sealants in primary molars: a SEM study. J Clin Pediatr Dent. 1994;18(3):187-90.

7. Waggoner WF, Siegal M. Pit and fissure sealant application: updating the technique. J Am Dent Assoc. 1996;127(3):351-61, quiz 391-2. doi:10.14219/jada.archive.1996.0205.

8. Nassar HM. Dental Caries Preventive Considerations: Awareness of Undergraduate Dental Students. Dent J (Basel). 2020;8(2). doi:10.3390/dj8020031.

9. Al-Maweri SA, Al-Jamaei AA, Halboub ES, Al-Soneidar WA, Tarakji B, Alsalhani A. Fissure sealants: Knowledge and practice of Yemeni dental practitioners. Eur J Dent. 2016;10(2):234238. doi:10.4103/1305-7456.178300.

10. Ealla KKR, Kumar AN, Turagam N, Sooraparaju SG, Yerrapothu RMR, Bhaskaran MK. Knowledge Analysis of Pit and Fissure Sealants among the Dental Students of South India. J Int Soc Prev Community Dent. 2018;8(6):508-512. doi:10.4103/jispcd.JISPCD $238{ }_{1} 8$. 